\title{
Radar cross sections for mesospheric echoes at Jicamarca
}

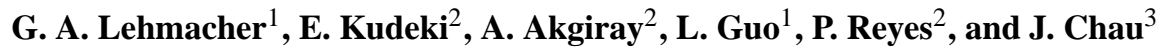 \\ ${ }^{1}$ Department of Physics and Astronomy, Clemson University, Clemson, SC, USA \\ ${ }^{2}$ Coordinated Science Laboratory, University of Illinois, Urbana-Champaign, IL, USA \\ ${ }^{3}$ Observatorio de Radio de Jicamarca, Instituto Geofisico del Perú, Lima, Peru
}

Received: 23 September 2008 - Revised: 11 March 2009 - Accepted: 29 June 2009 - Published: 6 July 2009

\begin{abstract}
Radar cross sections (RCS) of mesospheric layers at $50 \mathrm{MHz}$ observed at Jicamarca, Peru, range from $10^{-18}$ to $10^{-16} \mathrm{~m}^{-1}$, three orders of magnitudes smaller than cross sections reported for polar mesospheric winter echoes during solar proton events and six orders of magnitude smaller than polar mesospheric summer echoes. Large RCS are found in thick layers around $70 \mathrm{~km}$ that also show wide radar spectra, which is interpreted as turbulent broadening. For typical atmospheric and ionospheric conditions, volume scattering RCS for stationary, homogeneous, isotropic turbulence at $3 \mathrm{~m}$ are also in the range $10^{-18}$ to $10^{-16} \mathrm{~m}^{-1}$, in reasonable agreement with measurements. Moreover, theory predicts maximum cross sections around $70 \mathrm{~km}$, also in agreement with observations. Theoretical values are still a matter of order-of-magnitude estimation, since the Bragg scale of $3 \mathrm{~m}$ is near or inside the viscous subrange, where the form of the turbulence spectrum is not well known. In addition, steep electron density gradients can increase cross-sections significantly. For thin layers with large RCS and narrow spectra, isotropic turbulence theory fails and scattering or reflection from anisotropic irregularities may gain relevance.
\end{abstract}

Keywords. Ionosphere (Equatorial ionosphere) - Meteorology and atmospheric dynamics (Turbulence) - Radio science (Atmospheric propagation)

\section{Introduction}

The Jicamarca radar has the largest power-aperture product of all $50-\mathrm{MHz}$ radars (peak value $1.2 \times 10^{11} \mathrm{~W} \mathrm{~m}^{2}$ ). Therefore it is capable of observing very faint echoes from the atmosphere and ionosphere in great detail. This paper deals

Correspondence to: G. A. Lehmacher (glehmac@clemson.edu)

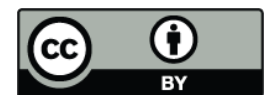

with turbulent echoes from the mesosphere, as seen from refractive index fluctuations at the Bragg scale of $3 \mathrm{~m}$. Mesospheric echoes at $50 \mathrm{MHz}$ have been observed at all latitudes and seasons (e.g. Reid, 1990), and 50-MHz radars are employed for Doppler wind measurements in the mesosphere, stratosphere, and troposphere (MST). While from the beginning of measurements at Jicamarca, scattering from turbulent structures was discussed as main mechanism for mesospheric echoes (Flock and Balsley, 1967; Woodman and Guillen, 1974; Rastogi and Bowhill, 1976), the discovery of very strong mesospheric summer echoes at VHF (Czechowsky et al., 1979; Ecklund and Balsley, 1981) and the study of aspect sensitivity at Jicamarca (Fukao et al., 1980; Kudeki, 1988) brought additional mechanisms into play, that help to explain the observed echo characteristics. For the very strong summer echoes, it is the extension and enhancement of the turbulent spectrum for electron fluctuations caused by reduced diffusivity and described by a large Schmidt number (Kelley et al., 1987). For aspect sensitivity, it is the presence of anisotropic scatterers, such as filaments or corrugated sheets of quasi-two-dimensional irregularities, formed in narrow layers by instabilities, that may cause partial or diffuse reflection or other deviations from isotropic scattering (Sheth et al., 2006).

Since Jicamarca mesospheric echoes are the archetype of VHF mesospheric echoes and can be observed on any given day, it is mandatory that turbulence theory shall be subjected to closer quantitative inspection. Comparisons across different radar systems are only meaningful when absolute radar cross sections (RCS) can be determined. This paper compares calibrated RCS for Jicamarca mesospheric echoes with predictions based on scattering from isotropic turbulence. The results are discussed in context with other radar measurements and numerical simulations of RCS.

(glehmac@clemson.edu)

Published by Copernicus Publications on behalf of the European Geosciences Union. 


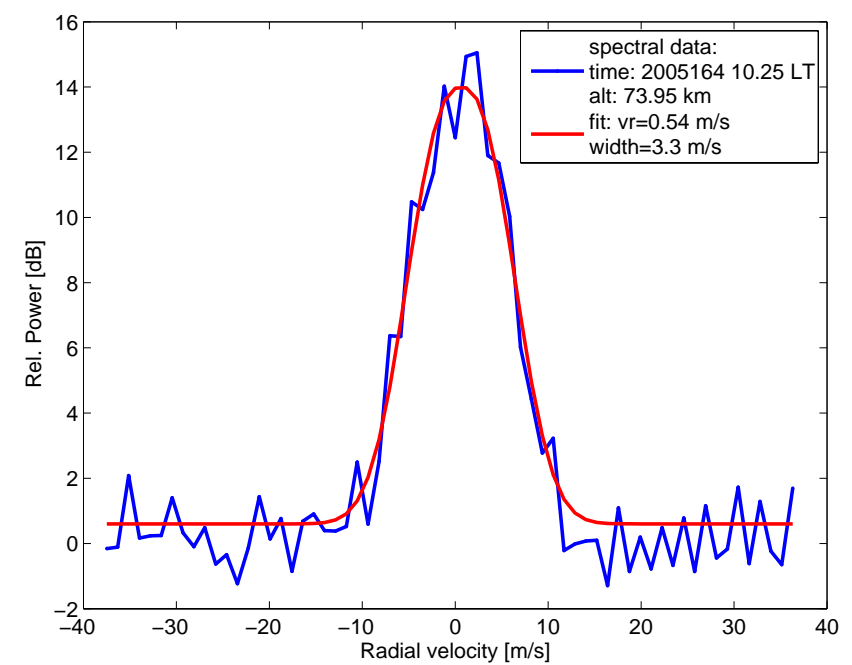

Fig. 1. Example spectrum of mesospheric echoes at Jicamarca. Coherent and incoherent spectra were added for each minute and $150 \mathrm{~m}$ range resolution. The smooth line is a generalized Gaussian fitted to the logarithm of the power spectrum (Sheth et al., 2006).

\section{Calibration of radar cross sections}

For calibration, we followed the approach first outlined by Woodman and Guillen (1974), using incoherent scatter from the F-region as calibration signal and scaling the F-region and D-region cross section with the respective pulse and integration times. Here we give an overview of the theory and implementation; it is fully described in the master's thesis by Akgiray (2007) and will be topic of a forthcoming paper.

The radar is operated in two modes quasi-simultaneously: a Mesosphere-Stratosphere-Troposphere (MST) mode with twenty pulses (64-baud complementary code, $1 \mu \mathrm{s}$ baud length, $150 \mathrm{~m}$ range resolution, $1.33 \mathrm{~ms}$ inter-pulse period, 9.6-200 km range) detecting weak coherent echoes, interleaved with an Incoherent Scatter Radar (ISR) mode using two pulses (3-baud Barker code, $106 \mu$ s baud length, $15.9 \mathrm{~km}$ range resolution, $66.7 \mathrm{~ms}$ inter-pulse period, 75$1000 \mathrm{~km}$ range). Hence, this operation is called MST-ISR mode. The 20 MST pulses are decoded and coherently integrated, 64-point FFT spectra are calculated, and 24 spectra each are added incoherently to form 1-min spectra. Each 53 ISR pulses are coherently integrated, decoded, transformed into 64-point FFT spectra, and 24 spectra are incoherently integrated for 1-min resolution. Finally, MST and ISR power profiles are calculated from the spectra. Spectral fitting allows us to estimate very small signals with spectral widths down to about $1 \mathrm{~m} / \mathrm{s}$. (Sheth et al., 2006; Guo et al., 2007). Figure 1 shows a fairly broad spectrum fitted by a generalized Gaussian to the logarithm of the power spectrum. Signal and width are calculated from the fitted spectrum. We calculate signal-to-noise ratio by summing over the entire spectrum, therefore values are very small for weak echoes and may range from -20 to $+20 \mathrm{~dB}$.
The ISR profiles are used to determine all relevant radar system parameters by modeling the received signal from the electron densities in the F-region. In principle, we use the known backscatter cross section of electrons in the ionosphere as calibration target, which is

$\sigma_{v} \approx 4 \pi r_{e}^{2} N_{e} /\left(1+T_{e} / T_{i}\right)$

The method is similar to measuring electron density profiles at Jicamarca with the Faraday rotation technique (Farley, 1969). The antenna configuration consists of four beams pointing $2.5^{\circ}$ off the vertical towards (magnetic) east, west, north, and south. None of the beams is perpendicular to the antenna plane or the earth magnetic field. The radar pulses are traveling at slightly different angles with respect to the magnetic field, and the polarization states of electric field vectors experience varying amounts of rotation in forward and backscattered directions. The Appleton-Hartree magneto-ionic theory is applied to describe the wave propagation and backscattered signal through E-region and Fregion, while magneto-ionic effects from the D-region can be neglected at $50 \mathrm{MHz}$. For our model, we assume propagation through a stratified ionosphere, which is divided into 100 horizontal slabs from 75 to $870 \mathrm{~km}$.

The antenna patterns for each of the four beams contain side lobes, which partially overlap each other (Sheth et al., 2006), and must be carefully modeled. In particular, receiving beams may contain different polarizations stemming from different transmitted beam patterns. Magneto-ionic rotation of field polarization as well as overlap of side lobes of various beams require discrete models for the beam patterns which are capable of resolving aforementioned crosspolarization terms. Each beam is therefore described by a sum of 43 finite elements with different beam weight factors based on the specific antenna pattern.

For electron profile retrieval, a linear combination of electric wave vectors is propagated through the ionosphere, calculating the incoherent backscatter from every slab, and collecting the backscattered waves propagating back to the antenna. The four beams are discretized based on the two-way antenna patterns as mentioned above. In order to account for all possible sources of discrepancy in transmission and reception, 13 calibration constants are introduced, nine of which are possibly complex. They include possible amplitude and phase mismatch $\eta$ of the transmission output splitter, eight transmission loss factors $\gamma_{i}$ for the four antenna quarters and for each polarization, and four calibration constants $\beta_{i}$ for the four receiver channels. The latter are scaled with the total transmitted power and the scattering volume depth. The backscattered power from a specific slab in the ionosphere, one point in the antenna beam, and one receiver channel (here, for example, East) is expressed by (Akgiray, 2007)

$$
\begin{aligned}
P_{E}= & \left(\beta_{1} / r^{2}\right)\left(W_{C} \sigma_{v}\left|v_{y y}\right|^{2}+W_{X} \sigma_{v}\left|v_{y z}\right|^{2}\right. \\
& \left.+2 \operatorname{Re}\left\{W_{H} \sigma_{v} v_{y y} v_{y z} *\right\}\right)
\end{aligned}
$$


where $W_{C, X, H}$ are beam weight factors, $\sigma_{v}$ the volume cross section for incoherent scatter (Eq. 1), and $v_{i j}$ are coefficients describing the geometry and coupling of the transmitted and received antenna polarizations based on the AppletonHartree theory. For the total received power for one channel, we must sum over all 43 antenna sampling points, including a system noise power, and add the contributions for all 100 slabs. Comparing Eq. (2) with the soft-target radar equation,

$$
P_{r}=\left(\delta r \lambda^{2} P_{t} /(4 \pi)^{3} / r^{2}\right) \int d \Omega G_{t} G_{r} \sigma_{v}
$$

where $\delta r$ is the scattering volume depth (twice the slab height), $P_{t}$ the transmitted power, and $G_{t} G_{r}$ the two-way gain pattern as a function of antenna angle, it can be seen that the calibration constant

$\beta=\left(\delta r \lambda^{2} P_{t} /(4 \pi)^{3} / L\right)$

while introducing an additional loss factor $L$ for each channel.

For the calibration, a regularized least-squares inversion algorithm (Tikhonov and Arsenin, 1977) was used to fit modeled power profiles to measured power data. The model is initialized by an electron density profile from the Jicamarca ionosonde, a triangular $T_{e} / T_{i}$ profile with a peak value of 2 below the F-region density maximum, and a constant ion temperature $T_{i}$ of $1000 \mathrm{~K}$. The minimization algorithm iteratively refines the estimates of $N_{e}, T_{e} / T_{i}, T_{i}$ profiles, noise levels, and calibration constants until convergence is reached. A set of electron density profiles is shown in Fig. 2, together with the profile obtained from the ionosonde.

Assuming isotropic backscatter, the D-region volume scattering coefficient or radar cross section (RCS) can be calculated from the radar equation using the measured received power and the calibration constants resulting from the electron density profile retrieval. Since the same antennas are used for MST and ISR modes, only the factors $\beta$ from Eq. (4) must be scaled as

$\beta_{D} / \beta_{F}=\left(P_{D} / P_{F}\right)\left(\delta r_{D} / \delta r_{F}\right)\left(w_{D}(t) / w_{F}(t)\right)$

where we assumed that the loss factors $L$ cancel, but introduce time-varying average noise powers $w(t)$. The Dregion measurements are taken at the highest nominal range resolution $(150 \mathrm{~m})$ possible for Jicamarca, requiring a wide bandwidth of $1 \mathrm{MHz}$ and equal to the antenna bandwidth, while the narrower bandwidth requirement for the F-region will not significantly reduce the return power. Thus the antenna bandwidth of $1 \mathrm{MHz}$ determines the received noise power, which at Jicamarca is dominated by galactic sky noise of more than $\sim 4000 \mathrm{~K}$. The received power scales with the pulse length and number of coherent integrations, $P_{D} / P_{F}=64 \cdot 20 /(2 \cdot 53 \cdot 3)$, and the scattering volume depths are $\delta r_{D} / \delta r_{F}=(0.15 \mathrm{~km}) /(15.9 \mathrm{~km})$. The sky noise varies with time, but the noise ratio is always close to unity.

Last, the two-way antenna gain calculations can be simplified for the D-region, since there is no significant rotation

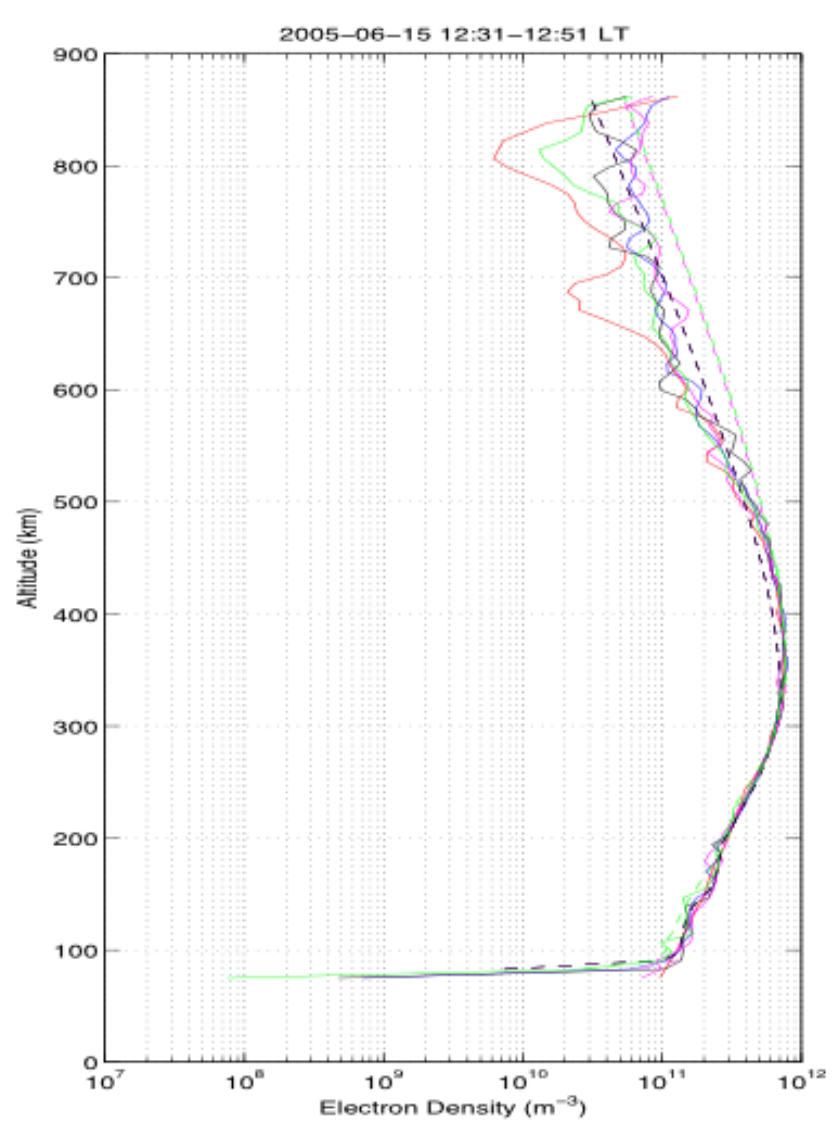

Fig. 2. Electron density profiles obtained with the MST-ISR mode (colored solid lines). The black dashed line shows the profile from the ionosonde analysis.

of the wave polarization. The final result for the D-region volume scattering coefficient (or radar cross section RCS) is

$\sigma_{v, D}=r^{2} P_{D} / \beta_{D} /\left(\int d \Omega G_{t} G_{r}\right)_{D}$

The calibration algorithm has been applied and tested on selected backscatter profiles, and first results are reported in this paper. Absolute radar cross sections allow comparisons with measurements from other radars and with theoretical calculations and model results.

\section{Results}

The first example displayed in Fig. 3 (top) is for a typical strong layer observed on 13 June 2005 (2005 164) near $73 \mathrm{~km}$ with three major patches of irregularities. Weaker layers are present above and below the main layer. Based on a previous study (Lehmacher et al., 2007), we interpret these strong echoes as three consecutive fields of KelvinHelmholtz waves advected through the radar beams. All four beams show similar echoes (not shown), since the radar scattering volumes are only $6 \mathrm{~km}$ apart. As explained above, range and time resolution is $150 \mathrm{~m}$ and $1 \mathrm{~min}$, respectively. 

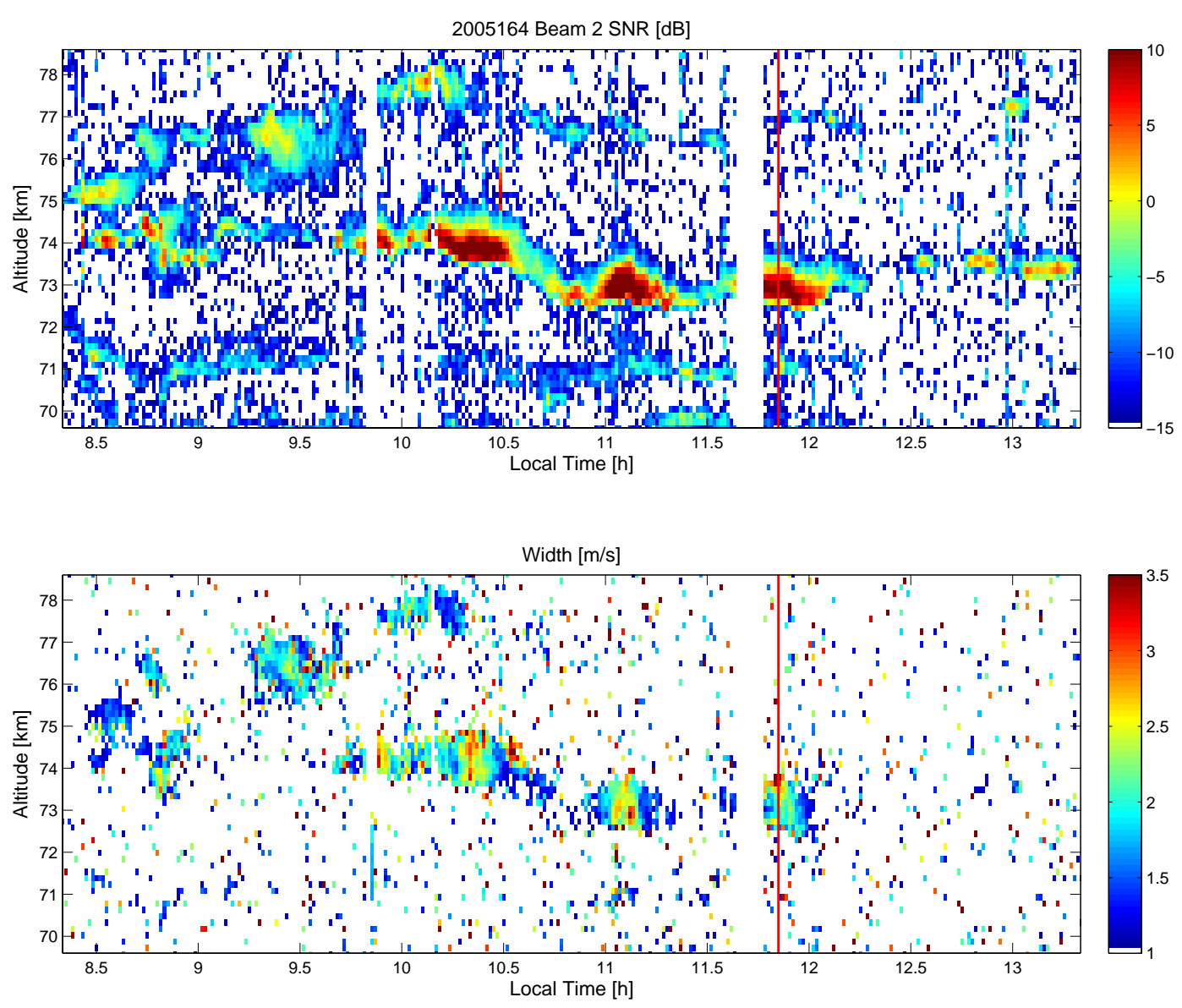

Fig. 3. Signal-to-noise ratio (top) and spectral width (bottom) showing a strong echo layer with relative wide spectra. The red line marks the time for which RCS profiles are shown in Fig. 5a.

The largest spectral widths in the three patches, shown in Fig. 3 (bottom), are between 2 and $3 \mathrm{~m} / \mathrm{s}$. We show spectral width only for echoes above $-10 \mathrm{~dB}$ SNR and for widths greater than $1 \mathrm{~m} / \mathrm{s}$, since values for very weak echoes are less reliable, and beam broadening effects contribute 0.1 to $0.7 \mathrm{~m} / \mathrm{s}$ to the spectral width (Guo et al., 2007). Wide spectra with positive power-width correlation are interpreted as caused by turbulent fluctuations (e.g., Hocking, 1985; Sheth et al., 2006) and have been used to derive turbulent energy dissipation rates for Jicamarca (Guo et al., 2007). Median turbulent energy dissipation rates estimated from spectral widths are around $10 \mathrm{~mW} / \mathrm{kg}$, but can vary between 1 and $100 \mathrm{~mW} / \mathrm{kg}$, with values generally increasing with altitude throughout the mesosphere. For our example, we simply state that the power and spectral width of the blob echoes is consistent with turbulent mesospheric echoes observed at Jicamarca.

The second example (Fig. 4) is from the following day, 14 June 2005 (2005 164), again showing a wide layer around $74 \mathrm{~km}$ with resolved tilted phase fronts and narrow layers above and below, which are strong at times indicated by the red and orange colors in the RTI. The wide layer has moderately broad spectra of $2 \mathrm{~m} / \mathrm{s}$, but the strong thin layers at $73 \mathrm{~km}$ have very narrow spectra, often below the cutoff in the plot of $1 \mathrm{~m} / \mathrm{s}$. We would like to point out that we can accurately determine spectral width for strong echoes as found in this event. After subtracting estimates for beam broadening, the remaining spectral width is less than $1 \mathrm{~m} / \mathrm{s}$. This means these layers would contain very low turbulence levels based on the interpretation of spectral width, but nevertheless contain strong scatterers.

In Fig. 5a we present profiles of RCS for all four beams sampling the third blob at $11.8 \mathrm{LT}$ (indicated in Fig. 3 by the vertical line). In this initial study, data from $5 \mathrm{~min}$ of data were averaged to perform the electron density retrieval and calculate RCS. All four beams show a very consistent picture with peak values close to $1 \times 10^{-16} \mathrm{~m}^{-1}$ in the center of the blob. The weaker layer is visible near $71 \mathrm{~km}$ with maximum values of $2 \times 10^{-18} \mathrm{~m}^{-1}$, still clearly above the minimum RCS levels of about $10^{-19} \mathrm{~m}^{-1}$. Our RCS include a small background contribution from incoherent scatter of $\sim 2 \pi r_{e}^{2} N_{e}$, which for $D$ region electron densities of $10^{8}$ 

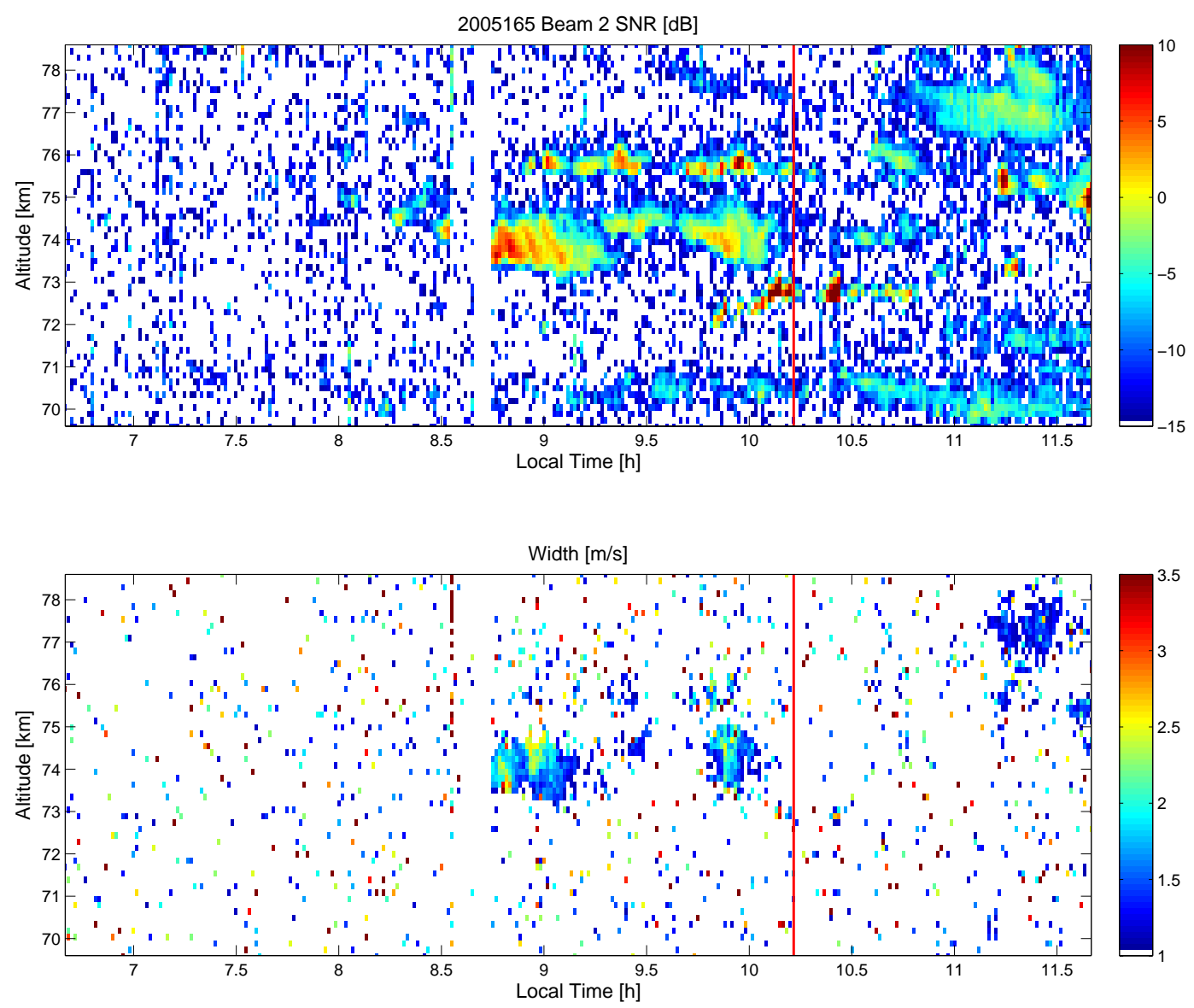

Fig. 4. Signal-to-noise ratio (top) and spectral width (bottom) showing a wide and some thin layers. Many echoes have very narrow spectra below the chosen cutoff of $1 \mathrm{~m} / \mathrm{s}$. The red line marks the profile shown in Fig. $5 \mathrm{~b}$.

to $10^{9} \mathrm{~m}^{-3}$ yields $\sim 5 \times 10^{-20}$ to $10^{-21} \mathrm{~m}^{-1}$. There is, however, not a consistent picture for very low RCS levels, therefore; values below $10^{-18} \mathrm{~m}^{-1}$ should be considered with caution. Figure $5 \mathrm{~b}$ shows the corresponding RCS for a profile at 10.2 LT for the echoes shown in Fig. 4, cutting through two thin layers near 72.5 and $75.5 \mathrm{~km}$. The thin layers are clearly visible and have peak reflectivities of $1 \times 10^{-17}$ and up to $1 \times 10^{-16} \mathrm{~m}^{-1}$. It is also remarkable that the reflectivity strongly varies for the four beams, which we interpret as aspect sensitivity.

These two examples are representative for the 96 profiles that have been evaluated for the initial study. We find that radar cross sections for mesospheric echoes at Jicamarca are typically between $10^{-18}$ and $10^{-16} \mathrm{~m}^{-1}$. Large cross sections occur in strong, wide layers with broad spectra associated with turbulence, but also in thin layers with narrow spectra with signs for aspect sensitivity. Next we will estimate radar cross sections in terms of volume reflectivity from basic turbulence theory which can be applied to layers with wide spectra.

\section{Estimates from turbulence theory}

The Kolmogorov theory for stationary, homogeneous, and isotropic turbulence has commonly been applied to radar backscatter and the result expressed as volume reflectivity or volume scattering coefficient (e.g., Tatarskii, 1971). For mesospheric echoes, the tracer for turbulence are refractive index fluctuations at the radar Bragg scale, $\lambda / 2=3 \mathrm{~m}$, due to electron density irregularities and caused by turbulent motion of air parcels. When comparing theoretical estimates with measurements, we compare volume reflectivities (as other publications call this quantity) with radar cross sections, but we recall that radar cross sections were calculated based on the assumption of volume scattering as explained in Sect. 2 . Therefore we will unequivocally refer to RCS for both the experimentally and theoretically derived quantities.

For the Jicamarca radar, turbulence theory has been applied first by Woodman and Guillen (1974), followed by Rastogi and Bowhill (1976). A comparison of RCS and in situ measured electron density fluctuations has been attempted by Røyrvik and Smith (1984). These early results fall in the same range as our measurements and will be discussed 
(a) 200516411.8 LT

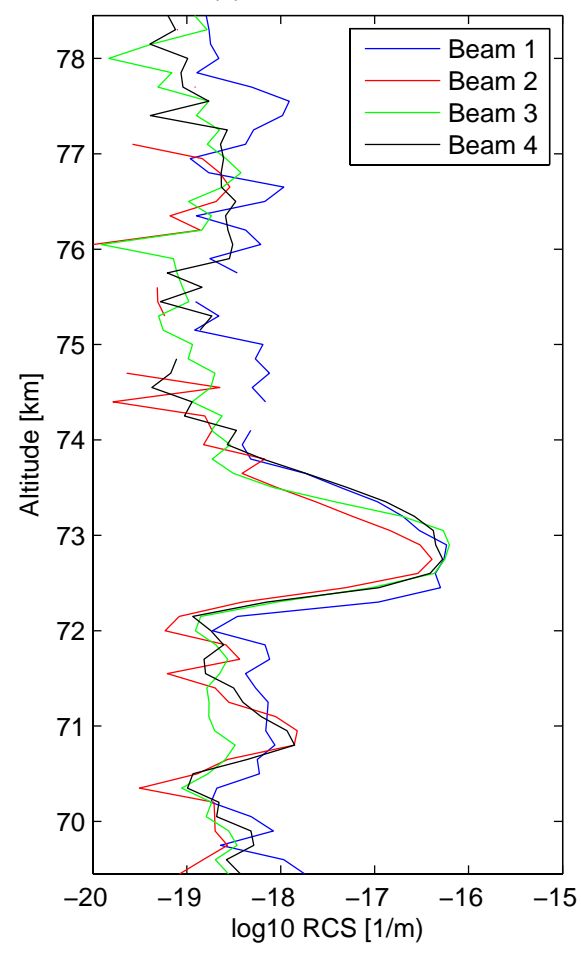

(b) $200516510.2 \mathrm{LT}$

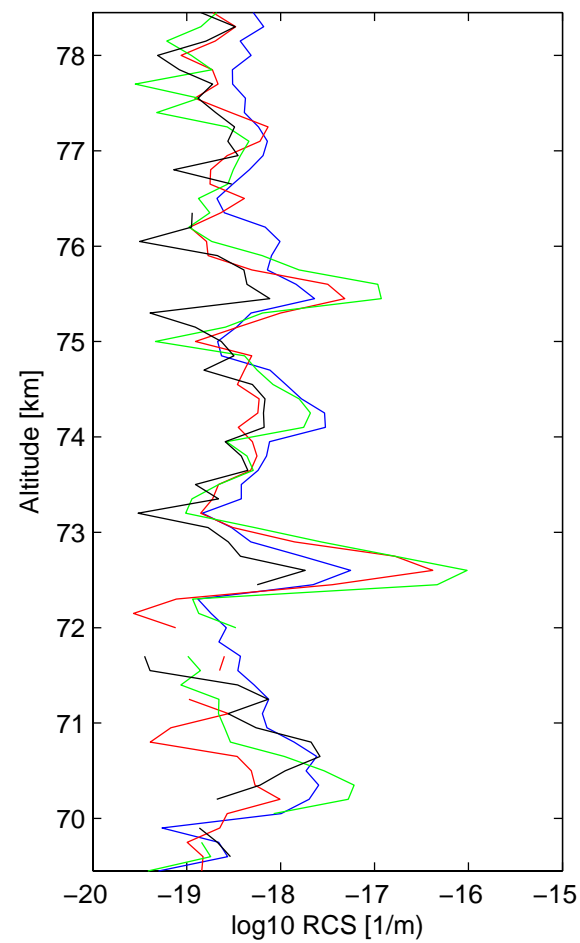

Fig. 5. Radar cross section (RCS) profiles for all four off-axis beams corresponding to the times marked with red lines in Figs. 3 and 4 . For this paper, data were averaged for five minutes to retrieve F-region profiles and radar calibration parameters. Example (a) shows a strong, wide layer with little differences between the four beam directions. Example (b) includes for two narrow layers with large RCS differences, usually expressed as aspect sensitivity.

below. More recently, RCS were calculated and compared with turbulence theory for intense $50-\mathrm{MHz}$ echoes from the winter mesosphere during solar proton events, which caused very strong electron density enhancements (Stebel et al., 2004; Lübken et al., 2006; Zeller et al., 2006). Following these authors who base their description of the turbulence spectrum on Heisenberg (1948), Driscoll and Kennedy (1985), and Hocking (1985), we write the volume reflectivity $\mathrm{RCS}$ as

$$
R C S=A r_{e}^{2} N_{e}^{2} \varepsilon^{2 / 3}\left(R i / \omega_{B}^{2} / \operatorname{Pr}\right)(G r a d)^{2} f\left(k, k_{0}, S c\right)
$$

with

$r_{e}$ classical electron radius

$N_{e}$ electron density

$\varepsilon$ turbulent energy dissipation rate

$R i$ Richardson number

$\omega_{B}$ Brunt-Vaisala or buoyancy frequency

Pr turbulent Prandtl number.

$\operatorname{Grad}=\omega_{B}^{2} / g+1 / H_{e}-1 / H_{n}$

is a gradient term describing the background temperature and electron density gradient with $H_{e}, H_{n}$ electron and neutral density scale height, and $f$ is a function describing the iner- tial and viscous subrange evaluated at the Bragg wavenumber $k$

$f\left(k, k_{0}\right)=k^{-11 / 3} /\left(1+\left(k / k_{0}\right)^{8 / 3}\right)^{2}$

based on Heisenberg's $k^{-7}$ description of the viscous subrange with $k_{0}=2 \pi / 9.9 \eta$

$\eta=2 \pi / k_{\eta}=\left(v^{3} / \varepsilon\right)^{1 / 4}$ Kolmogorov microscale,

$\nu=\mu / \rho$ kinematic viscosity, where $\rho$ is neutral mass density, or

$f\left(k, k_{0}, S c\right) \sim k^{-11 / 3} /\left(1+\left(k / k_{c}\right)^{6 / 3}\right)^{2}$

based on Driscoll and Kennedy's spectrum for small Schmidt numbers (Stebel et al., 2004) with

$k_{c}=S c^{3 / 4} k_{0}$ and $S c=D_{e} / D_{n}$ Schmidt number for electrons. The constant $A=8 \pi^{2} 0.033 f_{\alpha} a^{2}$ with the Kolmogorov number $a^{2}=1.74$ and $f_{\alpha}=2$ as discussed in Lübken (1992).

The Schmidt number plays a role in the presence of charged aerosols, effectively increasing the turbulent cross section by decreasing the diffusivity of electrons. This is the case near the cold polar summer mesopause, giving rise to very strong radar echoes (PMSE). For winter echoes and low latitude echoes, it is often assumed $S c \sim 1$. We note that the two functions $f\left(k, k_{0}\right)$ and $f\left(k, k_{0}, S c\right)$ show a different spectral form for $k>k_{0}$. A third form was used by Rastogi and Bowhill (1976), who included an intermediate range 


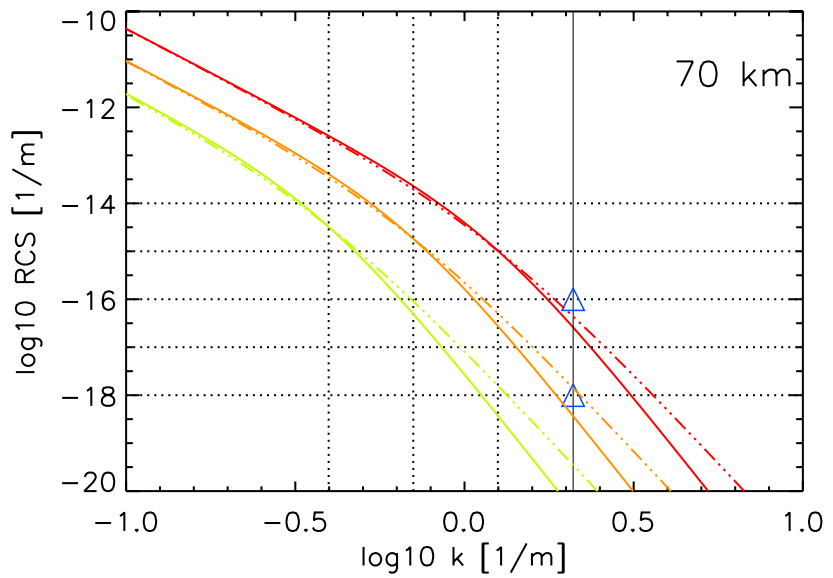

Fig. 6. Volume reflectivity RCS as function of wave number $k$ for conditions at $70 \mathrm{~km}$. The three sets of curves correspond to $\varepsilon=0.001,0.010,0.100 \mathrm{~W} / \mathrm{kg}$, values typical for Jicamarca, each for the Heisenberg (solid lines) and the Driscoll and Kennedy model for $S c \sim 1$ (dash-dotted lines). The vertical line indicates the radar Bragg wavenumber $2 \pi /(3 \mathrm{~m})$; the markers values of $10^{-16}$ and $10^{-18} \mathrm{~m}^{-1}$.

with $k^{-7}$ from $0.169 k_{\eta}$ to $0.738 k_{\eta}$ followed by an exponential falloff (Tchen, 1973), and which is similar to the two forms considered here.

Since many parameters are not well known when using the models above, we make the following assumptions. We choose electron profiles from the International Reference Ionosphere IRI-2000 (Bilitza, 2001) with the D-region description from Friedrich and Torkar (2001), and neutral temperatures and densities from the empirical model atmosphere NRLMSISE-00 (Picone et al., 2002). Then we calculate volume reflectivities $\sigma$ for three levels of turbulent activity, $\varepsilon=0.001,0.01$, and $0.1 \mathrm{~W} / \mathrm{kg}$. These values are generally observed in the mesosphere by radar and rockets (e.g., Fukao et al., 1994; Lübken, 1997), and also at Jicamarca (Guo et al., 2007). While the Richardson number or rather the horizontal wind shear $R i / \omega_{B}^{2}$ can be determined from Jicamarca winds, we are here interested in an average value and use $R i=0.81$ as in other papers. We take $P r=1$, and $S c=1$ as mentioned before. Another uncertainty is the fill factor $F$, expressing the fraction of the radar volume that is filled with scatterers. The choice $F=1$ will deliver an upper estimate for the volume scattering coefficient (Stebel et al., 2004), or, rather, a lower estimate for our measured RCS.

Figure 6 shows the spectra for such "standard" conditions at $70 \mathrm{~km}$ in a $\log$ - $\log$ plot. We include both model descriptions $f\left(k, k_{0}\right)$, since they differ considerably at $k=2 \pi /(3 \mathrm{~m})=2.094 \mathrm{~m}^{-1}$ and small $\varepsilon$ values. It is clear from these curves that the Bragg scale (indicated by the vertical line) is inside the viscous subrange just beyond the "break" in the spectrum, as first discussed by Rastogi and Bowhill (1976). Woodman and Guillen (1974) estimated a value of

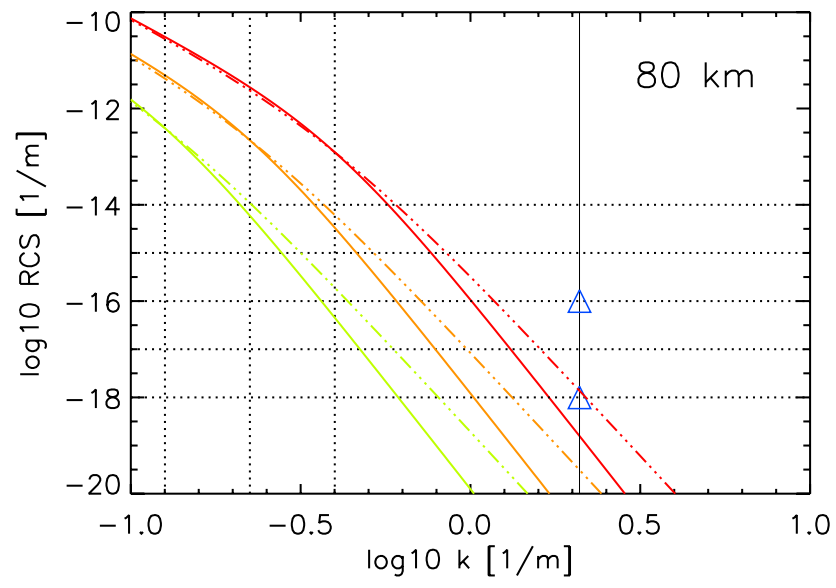

Fig. 7. Same as Fig. 6, but for conditions at $80 \mathrm{~km}$. The spectral break is at smaller wavenumbers. Notice how a value of $10^{-18} \mathrm{~m}^{-1}$ already requires $\sim 100 \mathrm{~mW} / \mathrm{kg}$, a relatively large value for the turbulent energy dissipation rate.

$1 \times 10^{-18} \mathrm{~m}^{-1}$ based on a constant $k^{-11 / 3}$ spectrum without viscous falloff. An important factor enhancing RCS is the electron density gradient, which can easily be larger by a factor of ten, thereby locally increasing RCS hundred times. The triangles mark the observed range $10^{-18}$ and $10^{-16} \mathrm{~m}^{-1}$ as shown in the previous section.

The next case (Fig. 7) considers conditions at $80 \mathrm{~km}$. Since neutral density is much lower and kinetic viscosity much higher, the spectral transition occurs at larger scales (smaller wave numbers). Røyrvik and Smith (1984, RS84) estimated a value of $\mathrm{RCS} \sim 2 \times 10^{-18} \mathrm{~m}^{-1}$ and $\varepsilon \sim 0.05 \mathrm{~W} / \mathrm{kg}$. Figure 7 indicates RCS levels of $1 \times 10^{-18}$ and $1 \times 10^{-16} \mathrm{~m}^{-1}$, which shows that the former value corresponds to high, but reasonable $\varepsilon \sim 100 \mathrm{~mW} / \mathrm{kg}$. It should be noted that RS84 estimated RCS using SNR and radar system parameters without absolute calibration and for a range gate of $3 \mathrm{~km}$. The main point is that at $80 \mathrm{~km}$ or above, it becomes more and more difficult to observe strong VHF echoes caused by neutral turbulence without the presence of significant aerosol particles.

For comparison, Fig. 8 shows the case for polar mesospheric winter echoes as observed and discussed by Stebel et al. (2004) and Lübken et al. (2006). Electron densities were dramatically enhanced around $70 \mathrm{~km}$ (by a factor of 100) due to solar proton flux resulting in values of greater than $10^{10} \mathrm{~m}^{-3}$. The turbulence model yields volume reflectivities of $10^{-15}$ and $10^{-14} \mathrm{~m}^{-1}$ for $\varepsilon$ of 0.010 and $0.100 \mathrm{~W} / \mathrm{kg}$ (Stebel et al., 2004). Both studies conclude that neutral turbulence was likely the cause of the fluctuations at $3 \mathrm{~m}$, observed by $50-\mathrm{MHz}$ radars with relatively small power-aperture products. Even larger cross sections of typically $10^{-14}$ to $10^{-12} \mathrm{~m}^{-1}$ (at $50 \mathrm{MHz}$ ) are measured for polar mesospheric summer echoes (Röttger et al., 1990; Rapp and Lübken, 2004). Despite their high altitude $(80-90 \mathrm{~km})$, the Schmidt number effect increases the level of fluctuations at 


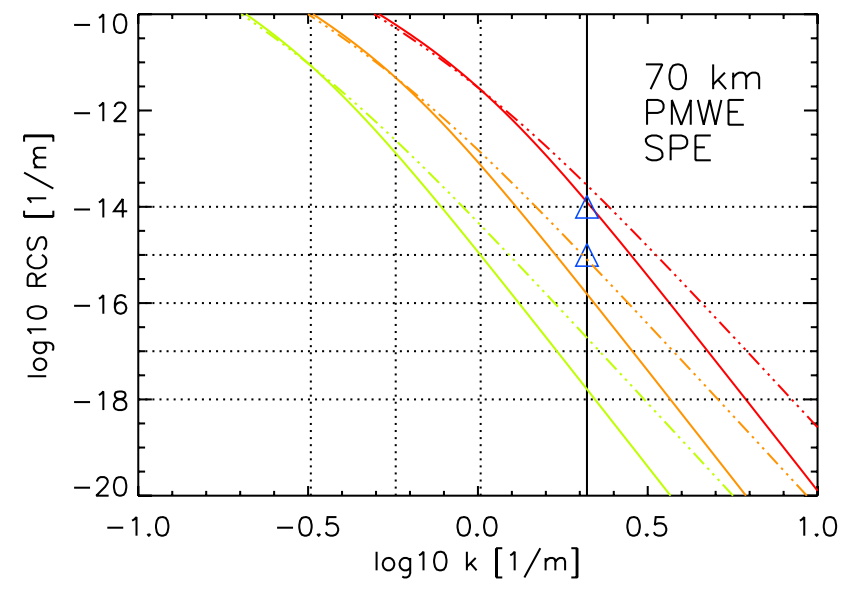

Fig. 8. Same as Fig. 6, but for conditions of strong polar mesospheric winter echoes during solar proton events as reported by Stebel et al. (2004) and Lübken et al. (2005). The spectrum is enhanced by large electron densities. Marked are values of $10^{-15}$ and $10^{-14} \mathrm{~m}^{-1}$.

$3 \mathrm{~m}$, which is 10000 times larger than the strongest echoes observed at Jicamarca.

Finally, we have plotted theoretical altitude profiles of the RCS using the model conditions based on IRI and MSIS (Fig. 9). For a constant level of turbulence, RCS decreases with altitude, and is mainly the effect of the increasing inner scale. The thick line uses epsilon values increasing from 0.010 to $0.100 \mathrm{~mW} / \mathrm{kg}$ according to Jicamarca observations (Guo et al., 2007), which will somewhat equalize the RCS spread. While there is a large variability in individual layers, the main point is that the largest RCS appear around $70 \mathrm{~km}$, which is consistent with the main level of echo layers observed at Jicamarca, which is between 70 and $75 \mathrm{~km}$. However, it must be repeated that there are also echoes, which do not conform to this very simple picture of isotropic turbulence, as shown in the examples above. It should be noted that a long record of mid- and high latitude winter echoes (Ecklund and Balsley, 1981) and more recently Zeller et al. (2006) also finds the maximum occurrence near $70 \mathrm{~km}$, even though that these observations took place during particle precipitation and enhanced D-region ionization.

\section{Discussion}

Our results extend the earlier estimates of radar cross sections for Jicamarca (Woodman and Guillen, 1974) and provide a more detailed picture of the variability of RCS across broad and narrow echo layers. Determining absolute cross sections allows a comparison with data from other calibrated $50-\mathrm{MHz}$ radars and predictions from simple turbulence theory, which interprets the RCS as volume reflectivity averaged over the radar pulse volume. Measured and calculated RCS range between $10^{-18}$ and $10^{-16} \mathrm{~m}^{-1}$ and are the smallest val-

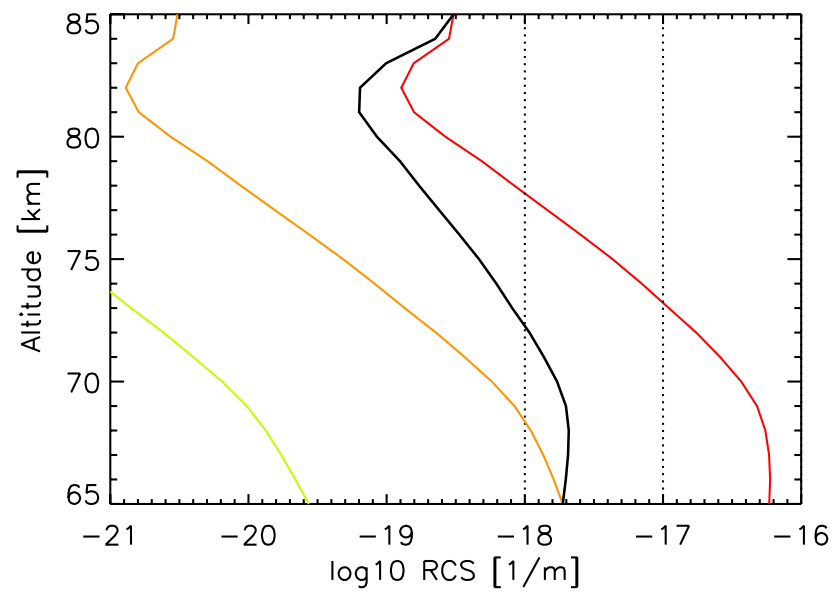

Fig. 9. Profiles of RCS for Bragg scale of $3 \mathrm{~m}$ and standard conditions at Jicamarca. The three colored lines are for levels $\varepsilon=0.001$, $0.010,0.100 \mathrm{~W} / \mathrm{kg}$. The thick line is for an $\varepsilon$ profile increasing from $0.010 \mathrm{~W} / \mathrm{kg}$ at $65 \mathrm{~km}$ to $0.100 \mathrm{~W} / \mathrm{kg}$ at $85 \mathrm{~km}$ as inferred from spectral widths (Guo et al., 2007).

ues reported for mesospheric echoes. The lower boundary is the threshold for our measurements. Agreement with standard turbulence theory can only be expected when the spectra are significantly broadened as additional indicator for turbulent motions. For isotropic turbulence, spectral width and echo power are positively correlated for most layers as shown by Sheth et al. (2006).

However, it also generally accepted that the assumption of stationary, homogeneous, isotropic turbulence throughout the layer is a gross oversimplification and may apply only occasionally during the development of an instability or wave breaking event. The Jicamarca high-resolution mesospheric echoes contain many examples of complex echo layers with large variations of power and spectral width. Some layers show enhanced edges, braided and cat eyes structures characteristic for Kelvin-Helmholtz instability (Lehmacher et al., 2007).

Direct numerical simulations (DNS) of wave breaking and Kelvin-Helmholtz (KH) instabilities (Fritts et al., 1996; Werne and Fritts, 1999), have significantly contributed to our understanding how and where turbulence develops in a model volume. In particular, the vorticity of the fluid motion is often concentrated in sheets or filaments, which are aligned with phase fronts. Recently, Fritts and coworkers (personal communication, 2008) calculated and discussed radar cross sections and spectra based on fluid simulations. The work is an extension of earlier work by Gibson-Wilde et al. (2000), which was an application for polar mesospheric summer echoes.

The new simulations were probed with virtual radars operating at $3 \mathrm{MHz}$ and $10 \mathrm{MHz}$ with vertical and off-zenith beams and different pulse lengths. It is found that the anisotropy of scatterers at the radar Bragg scale and the 
motion of specular reflectors lead to biases of vertical velocities and spectral width. Biases are mostly evident where mixing destroys refractivity index fluctuations and the radar becomes insensitive to turbulence, and where aligned slanted structures persist in the restratification phase. Lower resolution has smaller velocity biases, but is obviously less accurate in depicting details of the instability. These studies presume that the anisotropies in the turbulence field extend to even smaller scales that become relevant to the Jicamarca $50 \mathrm{MHz}$ radar. Since the radar has observed many examples of $\mathrm{KH}$ instabilities, future comparative studies with models should assess radial velocities or potential biases.

\section{Conclusions}

We have presented the first profiles of absolute radar cross sections for Jicamarca mesospheric echoes, that have been obtained by modeling the incoherent scatter returns with four oblique MST beams and eliminating system parameters specific for each transmitter and receiver channel. The main results are:

1. Measured RCS range between $10^{-18}$ and $10^{-16} \mathrm{~m}^{-1}$, which is orders of magnitudes smaller than mesospheric measurements from smaller $50-\mathrm{MHz}$ radars at mid- and high latitudes, and is obviously a detectability advantage of the large Jicamarca radar.

2. At these small levels, mesospheric echoes are a common daily occurrence for normal D-region conditions, as opposed to large electron densities and gradients, necessary to paint the turbulent fluctuations at mid- and polar latitudes, or charged aerosols and small electron diffusivity that enhance backscatter during polar summer.

3. These low levels of RCS are mostly consistent with values derived for homogeneous, isotropic turbulence, without resorting to large Schmidt numbers or other small-scale dynamics. Polar mesospheric winter echoes have been shown compatible with the same theory, however are also controversially discussed.

4. Using levels of turbulence from observed spectral widths, turbulence theory predicts the strongest echoes near $70 \mathrm{~km}$. Most Jicamarca mesospheric echoes are observed between 70 and $75 \mathrm{~km}$. Above $75 \mathrm{~km}$, the Bragg scale is deeper down in the viscous subrange, suppressing electron fluctuations responsible for backscattering.

5. There are exceptions. Some layers have very strong echoes, but at the same time exhibit very narrow spectra, uncharacteristic for strong turbulence. Numerical simulation of radar spectra shows that strong gradients in the fluid field lead to significant deviations from isotropic turbulence. Anisotropic scattering may help explain the aspect sensitivity of such layers.
Our results confirm the earliest results and theories on Jicamarca echoes, which were obtained with much coarser range resolution, therefore describing an averaged view of the scattering layer. The current nominal resolution of $150 \mathrm{~m}$ is still much larger than the 3-m scale scattering structures, but has revealed intricate patterns in layers, that show enhanced edges or centers and large variations in spectral width and Doppler shift. At closer inspection, the structures are not homogeneous, stationary, or isotropic, and basic turbulence theory is rather a crude approximation.

Acknowledgements. This project has been funded by the National Science Foundation under Grants ATM-0422837 and ATM0422661. The Jicamarca Radio Observatory is a facility of the Instituto Geofísico del Perú and is operated with support from the NSF Cooperative Agreement ATM-0432565 through Cornell University.

Editor in Chief W. Kofman thanks one anonymous referee for her/his help in evaluating this paper.

\section{References}

Akgiray, A.: Calibration of Jicamarca radar using $F$ region incoherent scatter for measurement of D region backscatter RCS, MSc thesis, University of Illinois, 2007.

Bilitza, D.: International reference ionosphere 2000, Radio Sci., 36, 261-276, 2001.

Czechowsky, P., Rüster, R., and Schmidt, G.: Variations of mesospheric structures in different seasons, Geophys. Res. Lett., 6, 459-462, 1979.

Driscoll, R. J. and Kennedy, L. A.: A model for the spectrum of passive scalars in an isotropic turbulence field, Phys. Fluids, 28, 72-80, 1985.

Ecklund, W. L. and Balsley, B. B.: Long-term observations of the Arctic mesosphere with the MST radar at Poker Flat, Alaska, J. Geophys. Res., 86, 7775-7780, 1981.

Farley, D. T.: Faraday rotation measurements using incoherent scatter, Radio Science, 4(2), 143-152, 1969.

Flock, W. L. and Balsley, B. B.: VHF radar returns from the $D$ region of the equatorial ionosphere, J. Geophys. Res., 72, 55375541, 1967.

Friedrich, M. and Torkar, K. M.: FIRI: A semiempirical model of the lower ionosphere, J. Geophys. Res., 106, 21409-21418, 2001.

Fritts, D. C., Palmer, T. L., Andreassen, Ø., and Lie, I.: Evolution and breakdown of Kelvin-Helmholtz billows in stratified compressible flows, I: Comparison of two- and three-dimensional flows, J. Atmos. Sci., 53, 3173-3191, 1996.

Fukao, S., Sato, T., Harper, R. M., and Kato, S.: Radio wave scattering from the tropical mesosphere observed with the Jicamarca radar, Radio Sci., 15, 447-457, 1980.

Fukao, S., Yamanaka, M. D., Naoki Ao, Hocking, W. K., Sato, T., Yamamoto, M., Nakamura, T., Tsuda, T., and Kato, S.: Seasonal variability of vertical eddy diffusivity in the middle atmosphere 1. Three-year observations by the middle and upper atmosphere radar, J. Geophys. Res., 99, 18973-18987, 1994.

Gibson-Wilde, D., Werner, J., Fritts, D., and Hill, R.: Direct numerical simulations of VHF radar measurements of turbulence in the mesosphere, Radio Sci., 35, 783-798, 2000. 
Guo, L., Lehmacher, G. A., Kudeki, E., Akgiray, A., Sheth, R., and Chau, J.: Turbulent Energy Dissipation Rates and Eddy Diffusivities in the Tropical Mesosphere Obtained from Jicamarca Radar Data, J. Adv. Space Res., 40, 744-750, 2007.

Heisenberg, W.: Zur statistischen Theorie der Turbulenz, Z. Physik, 124, 628-657, 1948.

Hocking, W. K.: Measurements of turbulent energy dissipation rate in the middle atmosphere by radar technique: a review, Radio Sci., 20, 1403-1422, 1985.

Kelley, M. C., Farley, D. T., and Röttger, J.: The effect of cluster ions on anomalous VHF backscatter from the summer polar mesosphere, Geophys. Res. Lett., 14, 1031-1034, 1987.

Kudeki, E.: Radar interferometer observations of mesospheric echoing layers at Jicamarca, J. Geophys. Res., 93, 5413-5421, 1988.

Lehmacher, G. A., Guo, L., Kudeki, E., and Chau, J.: Highresolution observations of mesospheric layers with the Jicamarca VHF radar, J. Adv. Space Res., 40, 734-743, 2007.

Lübken, F.-J.: On the extraction of turbulent parameters from atmospheric density fluctuations, J. Geophys. Res., 97, 20385-20395, 1992.

Lübken, F.-J.: Seasonal variation of turbulent energy dissipation rates at high latitudes as determined by in situ measurements of neutral density fluctuations, J. Geophys. Res., 102, 1344113456, 1997.

Lübken, F.-J., Strelnikov, B., Rapp, M., Singer, W., Latteck, R., Brattli, A., Hoppe, U.-P., and Friedrich, M.: The thermal and dynamical state of the atmosphere during polar mesosphere winter echoes, Atmos. Chem. Phys., 6, 13-24, 2006, http://www.atmos-chem-phys.net/6/13/2006/.

Picone, J. M., Hedin, A. E., Drob, D. P., and Aikin, A. C.: NRLMSISE-00 Empirical Model of the Atmosphere: Statistical Comparisons and Scientific Issues, J. Geophys. Res., 102(A12), SIA 15-1, 1468, 2002.

Rapp, M. and Lübken, F.-J.: Polar mesosphere summer echoes (PMSE): Review of observations and current understanding, Atmos. Chem. Phys., 4, 2601-2633, 2004, http://www.atmos-chem-phys.net/4/2601/2004/.
Rastogi, P. K. and Bowhill, S. A.: Scattering of radio waves from the mesosphere- 2. Evidence for intermittent turbulence, J. Atmos. Terr. Phys., 38, 449-462, 1976.

Røyrvik, O. and Smith, L. G.: Comparison of mesospheric VHF radar echoes and rocket probe electron concentration measurements, J. Geophys. Res., 89(A10), 9014-9022, 1984.

Reid, I. M.: Radar observations of stratified layers in the mesosphere and lower thermosphere $(50-100 \mathrm{~km})$, Adv. Space Res., 10(10), 7-19, 1990.

Röttger, J., Rietveld, M. T., La Hoz, C., Hall, C., Kelley, M. C., and Swartz, W.: Polar mesosphere summer echoes observed with the EISCAT 933-MHz radar and the CUPRI $46.9 \mathrm{MHz}$ radar, their similarity to $224 \mathrm{MHz}$ radar echoes and their relation to turbulence and electron density profiles, Radio Sci., 25, 671-687, 1990.

Sheth, R., Kudeki, E., Lehmacher, G., Sarango, M., Woodman, R., Chau, J., Guo, L., and Reyes, P.: A high-resolution study of mesospheric fine structure with the Jicamarca MST radar, Ann. Geophys., 24, 1281-1293, 2006, http://www.ann-geophys.net/24/1281/2006/.

Stebel, K., Blum, U., Fricke, K.-H., Kirkwood, S., Mitchell, N. J., and Osepian, A.: Joint radar/lidar obser vations of possible aerosol layers in the winter mesosphere, J. Atmos. Solar Terr. Phys., 66, 957-970, 2004.

Tatarskii, V. I.: The Effects of the Turbulent Atmosphere on Wave Propagation, Keter Press, Jerusalem, 1971.

Tchen, C. M.: Repeated cascade theory of homogeneous turbulence, Phys. Fluids, 16, 13-30, 1973.

Tikhonov, A. N. and Arsenin, V. A.: Solutions of Ill-Posed Problems, Winston \& Sons, Washington, D.C., 1977.

Werne, J. A. and Fritts, D. C.: Stratified shear turbulence: Evolution and statistics, Geophys. Res. Lett., 26, 439-442, 1999a.

Woodman, R. F. and Guillen, A.: Radar observations of winds and turbulence in the stratosphere and mesosphere, J. Atmos. Sci., 31, 493-503, 1974.

Zeller, O., Zecha, M., Bremer, J., Latteck, R., and Singer, W.: Mean characteristics of mesosphere winter echoes at mid- and highlatitudes, J. Atmos. Solar-Terr. Phys., 68, 1087-1104, 2006. 